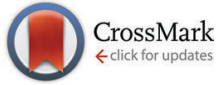

Cite this: J. Mater. Chem. C, 2015 3, 11886

Received 30th September 2015, Accepted 13th October 2015

DOI: $10.1039 / c 5 t c 03124 a$

www.rsc.org/MaterialsC

\section{Copper thiocyanate (CuSCN): an efficient solution-processable hole transporting layer in organic solar cells $\dagger$}

\begin{abstract}
Neeraj Chaudhary, ${ }^{a b}$ Rajiv Chaudhary, ${ }^{b}$ J. P. Kesari, ${ }^{b}$ Asit Patra*a and Suresh Chand $^{a}$
Here, we report copper(I)thiocyanate (CUSCN) as an efficient and solution-processable hole transport layer $(\mathrm{HTL})$ in bulk heterojunction solar cells. Three different combinations of the most studied active layers of P3HT:PC ${ }_{61} B M, P C D T B T: P C_{71} B M$ and PTB7:PC ${ }_{71} B M$ were used for photovoltaic device fabrication with the simplest device structure of ITO/CuSCN/active layer/Al. The use of CUSCN as an HTL has improved light absorption within the active layer and thereby leads to up to $5.94 \%$ and $4.60 \%$ power conversion efficiencies (PCEs) for the active layers of PCDTBT:PC ${ }_{71} B M$ and PTB7:PC 71 BM, respectively. These results are slightly better when compared to the devices fabricated using thermal deposition of $\mathrm{MoO}_{3}$ and solution processed deposition of PEDOT:PSS as an HTL under similar conditions. We have observed that the annealing temperature for HTLs in organic solar cells has a significant effect on the PCE, specifically the fill factor (FF) and short-circuit current $\left(J_{s c}\right)$. In the present work, the resulting HTLs were characterized using UV-vis-NIR spectroscopy, scanning electron microscopy (SEM), atomic force microscopy (AFM) and transmission electron microscopy (TEM) for better understanding. Finally, we have provided a further example of solution-processable CuSCN as an efficient HTL in organic solar cells, in general.
\end{abstract}

\section{Introduction}

Power conversion efficiency (PCE) with adequate stability in polymeric solar cells is the most crucial challenge for their possible commercial applications at a large scale. Conventional bulk heterojunction (BHJ) solar cells have been fabricated from a blend of active layers of a conjugated material (donor material) and a fullerene derivative (acceptor material) sandwiched between the hole transport layer (HTL) on an indium tin oxide (ITO) positive electrode and the electron transport layer (ETL) on a low-work-function metal negative electrode. Various methodologies have been developed for realizing this goal, among them active layer optimization and engineering are most studied. ${ }^{1,2}$ In contrast to active layer, very scant studies have been reported on HTLs, which can be the electrical contacts between active layers, and electrodes, and lead to enhancement of charge transport and collection. Thus the HTL in a photovoltaic device plays a

\footnotetext{
${ }^{a}$ CSIR-Network of Institutes for Solar Energy, Organic \& Hybrid Solar Cells Group, Physics of Energy Harvesting Division, CSIR-National Physical Laboratory, Dr. K. S. Krishnan Marg, New Delhi-110012, India. E-mail: apatra@nplindia.org ${ }^{b}$ Department of Mechanical Engineering, Delhi Technological University, Delhi-110042, India

$\dagger$ Electronic supplementary information (ESI) available: Detailed sample preparation and $J-V$ curves. This material is available free of charge via the internet. See DOI: $10.1039 / \mathrm{c} 5$ tc03124a
}

pivotal role in device stability, PCE, influencing the work function of the electrode and the properties of the active layer. It is also mentioned here that with respect to thousands of active materials (i.e. donor and acceptor materials) reported in the literature, ${ }^{3-5}$ the types of organic HTL materials are limited to poly(3,4-ethylenedioxythiophene):poly(styrene sulfonate) (PEDOT:PSS), polyaniline:poly(styrene sulfonate), graphene-based materials, carbon nanotubes (CNTs), etc. ${ }^{6}$

Water soluble PEDOT:PSS is the most widely used HTL in organic solar cells, while several investigations have demonstrated that due to the hygroscopic, acidic and protonation nature of PSS in PEDOT:PSS, it influences the device stability and degradation which limits their possible commercial applications. $^{7,8}$ It is also noted that other PSS based HTL materials like polyaniline have influenced the device stability. ${ }^{9,10}$ Small molecules, ${ }^{11}$ graphene-based materials ${ }^{12,13}$ and CNTs are also used as HTLs for organic solar cells; the PCE of these devices is poor compared to PEDOT:PSS used as an HTL. Alternatively transition metal oxides, like nickel oxide (NiO), molybdenum oxide $\left(\mathrm{MoO}_{x}\right)$, vanadium oxide $\left(\mathrm{V}_{2} \mathrm{O}_{5}\right)$, tungsten oxide $\left(\mathrm{WO}_{3}\right)$, etc., have been widely used as efficient HTLs as replacements for PEDOT:PSS in organic solar cells. ${ }^{14-19}$ It is also noted that for some transition metal oxides, a thermally deposited HTL is required for better photovoltaic performance. For example the thermally deposited $\mathrm{MoO}_{x}$ has been reported as an excellent 
HTL in organic solar cells and shows very promising performances compared to PEDOT:PSS as an HTL. ${ }^{14}$

Copper(I)thiocyanate (CuSCN) $)^{20-22}$ is successfully used as an HTL that exhibits both high optical transparency and p-type conductivity. ${ }^{23}$ Most importantly, CuSCN works excellently from solution using appropriate solvents and concentration at room temperature, ${ }^{24}$ thus making it a suitable solution-processable HTL for cost effective, large area and flexible plastic substrate applications. CuSCN was reported as an efficient HTL for dye synthesized solar cells ${ }^{24}$ and hybrid perovskite solar cells. ${ }^{25}$ Recently, electrodeposited CuSCN as an efficient HTL for BHJ solar cells ${ }^{26}$ and perovskite solar cells ${ }^{27}$ has been reported. The poor solubility of CuSCN limits its application as a solutionprocessable HTL for solar cell applications. So far two useful solvents diisopropyl sulfide and diethyl sulfide have been reported for CuSCN at appropriate concentration to reach the minimum thickness required for an HTL in solar cell applications.

To the best of our knowledge, very recently, only two studies have been demonstrated for CuSCN as a solution-processable and transparent HTL in BHJ solar cells using different combinations of donor and acceptor materials. ${ }^{28,29}$ Yaacobi-Gross et al. first demonstrated solution-processable CuSCN as an HTL material for high efficiency organic solar cells using a bilayer Sm/Al (10/90 nm) cathode for device fabrication. ${ }^{28} \mathrm{CuSCN}$ as a solution-processable HTL was not studied for the most used active materials of poly(3-hexylthiophene) and phenyl- $\mathrm{C}_{61}$-butyric acid methyl ester (P3HT:PC $\left.{ }_{61} \mathrm{BM}\right){ }^{30}$ poly[ $N$-9'-heptadecanyl-2,7-carbazolealt-5,5-(4',7'-di-2-thienyl-2 $2^{\prime}, 1^{\prime}, 3^{\prime}$-benzothiadiazole)] (PCDTBT) ${ }^{31}$ and poly[[4,8-bis[(2-ethylhexyl)oxy]benzo[1,2- $\left.b: 4,5-b^{\prime}\right]$ dithiophene2,6-diyl][3-fluoro-2-[(2-ethylhexyl)carbonyl] thieno[3,4- $b]$ thiophenediyl]] (PTB7) ${ }^{32}$ blend with phenyl- $\mathrm{C}_{71}$-butyric acid methyl ester $\left(\mathrm{PC}_{71} \mathrm{BM}\right)$.

Here we report CuSCN as an efficient and solution-processable HTL in conventional BHJ solar cells. Three different combinations of active layers of P3HT:PC 61 BM, PCDTBT:PC ${ }_{71} \mathrm{BM}$ and PTB7:PC ${ }_{71} \mathrm{BM}$ were used for photovoltaic device fabrication with the simplest device structure of ITO/CuSCN/active layer/Al. Detailed investigation of the effect of annealing temperature of the HTL on photovoltaic performances was done. In the present work, the resulting HTLs were characterized using UV-vis-NIR spectroscopy, scanning electron microscopy (SEM), atomic force microscopy (AFM) and transmission electron microscopy (TEM) for a better understanding to achieve the highest possible efficiency.

\section{Experimental}

\subsection{Device fabrication}

The organic photovoltaic devices with the geometry of glass/ ITO/CuSCN/active layer/Al were fabricated on ITO coated glass substrates. Prior to use, the substrates were cleaned with soap solution followed by deionized water. Then the substrates were refluxed in acetone followed by trichloroethane and isopropanol, respectively. After drying the substrates and UV-ozone treatment of the ITO substrate, a thin film of the CuSCN (30 nm) layer was spin coated at $3000 \mathrm{rpm}$ for 60 seconds. The resulting thin films were annealed (at $90{ }^{\circ} \mathrm{C}$ for 20 minutes and $120{ }^{\circ} \mathrm{C}$ for 20 minutes) and then dried at room temperature for 1 hour under ambient conditions. Three different active materials (P3HT:PC ${ }_{61} \mathrm{BM}$, PCDTBT:PC ${ }_{71} \mathrm{BM}$ and $\mathrm{PTB} 7: \mathrm{PC}_{71} \mathrm{BM}$ ) were used to investigate the efficiency of the HTL. Active materials were spin coated on top of CuSCN as an HTL at $1000 \mathrm{rpm}$ for 90 seconds and the resulting substrates were further annealed at $70{ }^{\circ} \mathrm{C}$ for 10 minutes (P3HT:PC ${ }_{61} \mathrm{BM}$ was baked for $120{ }^{\circ} \mathrm{C}$ for 10 minutes). Finally the devices were completed by the deposition of a $120 \mathrm{~nm}$ aluminium layer at a pressure of $5 \times 10^{-6}$ mbar.

\subsection{Device characterization}

All the device measurements were performed under ambient conditions without a protective atmosphere. The currentvoltage $(J-V)$ characteristics and PCE were measured using a computer controlled Keithley 2400 sourcemeter. To measure the current density under illumination, the devices were illuminated from the transparent ITO electrode side using a solar simulator with an air mass of 1.5G (AM 1.5G) (100 $\left.\mathrm{mW} \mathrm{cm}^{-2}\right)$. UV/Vis spectra were obtained on a UV-1800 Shimadzu spectrophotometer and AFM images were obtained on a NT-MDT Solver Pro. SEM and TEM images of CuSCN films were measured using a Zeiss EVO MA-10, and variable pressure and EDS were measured on an Oxford INCA Energy 250 and a Tecnai, TF30 M/s FEI, respectively.

\section{Results and discussion}

\subsection{Photovoltaic properties}

Inspired by the high potential importance of CuSCN as a solution-processable HTL over PEDOT:PSS and other transition metal oxides, we decided to explore the solution-processable CuSCN as an HTL in organic solar cells in general. To examine the CuSCN films as HTLs in photovoltaic devices, BHJ solar cells were fabricated using the simplest device geometry of ITO/ CuSCN/active layer/Al as presented in Fig. 1. It is well-known that P3HT:PC ${ }_{61} \mathrm{BM}$, PCDTBT:PC ${ }_{71} \mathrm{BM}$ and PTB7:PC ${ }_{71} \mathrm{BM}$ are the most studied and successfully used donor:acceptor combinations

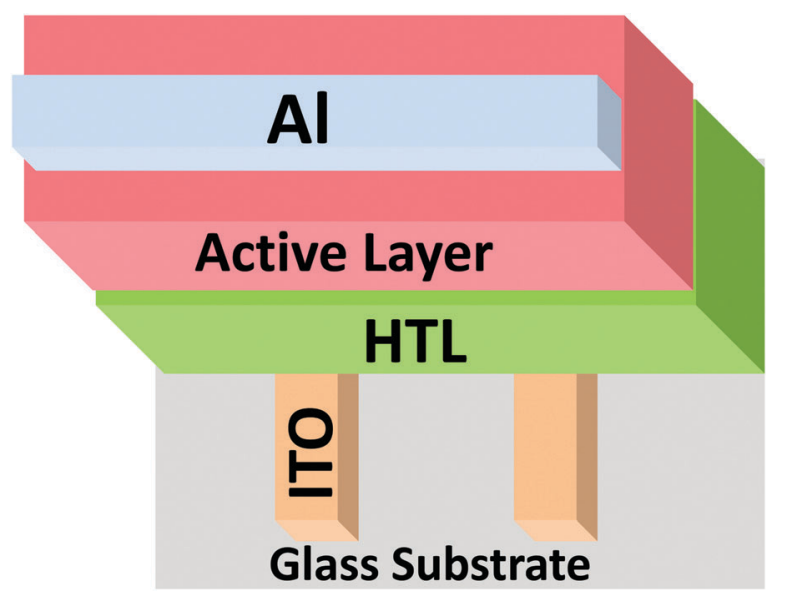

Fig. 1 Schematic of the conventional BHJ solar cell in which the HTL is sandwiched between an ITO anode and the active layer. 


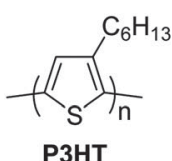

P3HT

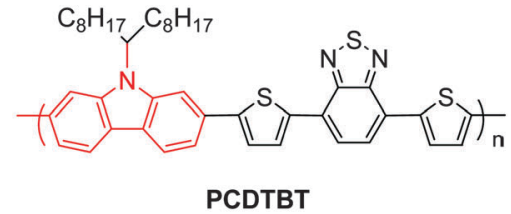

PCDTBT

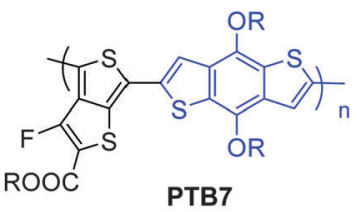

$\mathrm{R}=$ 2-ethylhexyl

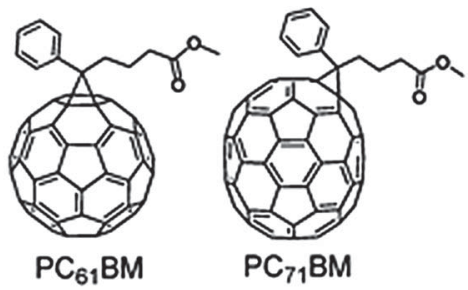

Fig. 2 Chemical structures of P3HT, PCDTBT, PTB7, $\mathrm{PC}_{61} \mathrm{BM}$ and $\mathrm{PC}_{71} \mathrm{BM}$.

in organic solar cells based on PEDOT:PSS and other transition metal oxides as HTLs. We have examined the efficiency of these donor:acceptor combinations using solution-processable CuSCN as an HTL in order to obtain more universal applications. The chemical structures and the band diagram of the materials used are presented in Fig. 2 and 3, respectively.

A blend of $\mathrm{P} 3 \mathrm{HT}$ and $\mathrm{PC}_{61} \mathrm{BM}$ active materials are the most studied donor and acceptor materials, respectively, in organic solar cells. To examine the performance of the active layer using CuSCN as an HTL, CuSCN in diisopropyl sulfide was spincoated onto the pre-patterned ITO electrode on a glass substrate for device fabrication. The thickness of the HTL was varied by using different concentrations of the solution and rpm during spin casting followed by annealing. Then the $\mathrm{P} 3 \mathrm{HT}: \mathrm{PC}_{61} \mathrm{BM}(1.0: 0.8 \mathrm{wt} \%)$ active layer from a solvent of chlorobenzene was deposited and finally the device was completed by the deposition of a $120 \mathrm{~nm}$ aluminium layer at a pressure of $5 \times 10^{-6} \mathrm{mbar}$. We have observed that these devices show poor performance. ${ }^{33}$ This may be due to the compatibility issue between the HTL and the active layer, namely interfacial energy alignment occurs due to the significant difference between the work function of CuSCN $(-5.35 \mathrm{eV})$ and the highest occupied molecular orbital (HOMO) level of P3HT $(-4.90 \mathrm{eV})$, but further studies will be needed to confirm this proposal.

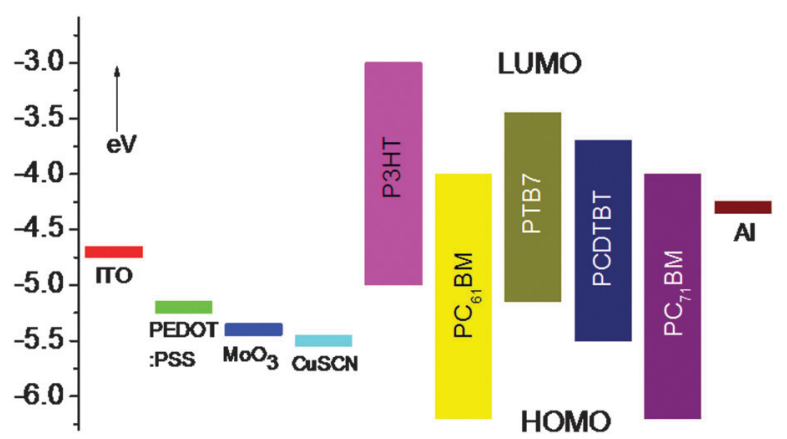

Fig. 3 Electronic energy levels of the materials used in organic solar cells.
To demonstrate solution-processable CuSCN as a potential HTL for low band gap donor polymers, BHJ solar cells were fabricated with well studied PCDTBT as a donor polymer with $\mathrm{PC}_{71} \mathrm{BM}$ as an acceptor material using a simple device structure of ITO/CuSCN/PCDTBT:PC ${ }_{71} \mathrm{BM} / \mathrm{Al}$. All the devices were fabricated and characterized under identical ambient conditions and the photovoltaic results under AM 1.5G illumination with $100 \mathrm{~mW} \mathrm{~cm}{ }^{-2}$ are summarized in Table 1 . CuSCN as an HTL layer was deposited from a solution of diisopropyl sulfide and the thickness of the layer is about $30 \mathrm{~nm}$. The resulting HTL was thermally annealed by heating at $90{ }^{\circ} \mathrm{C}$ for 20 minutes. Then the active material PCDTBT: $\mathrm{PC}_{71} \mathrm{BM}(1.0: 4.0 \mathrm{wt} \%)$ was deposited on the annealed HTL followed by further annealing and deposition of a $120 \mathrm{~nm}$ aluminium layer at a pressure of $5 \times 10^{-6} \mathrm{mbar}$. We have found that the resulting device shows a PCE of $4.22 \%$ with the open circuit voltage $\left(V_{\text {oc }}\right)$, short-circuit current $\left(J_{\mathrm{sc}}\right)$ and fill factor $(\mathrm{FF})$ being $0.76 \mathrm{~V}, 14.89 \mathrm{~mA} \mathrm{~cm}^{-2}$ and 37.39, respectively, as shown in Fig. 4. We have noted that thermal annealing of the HTL has an influence on device performances namely FF. Under identical conditions, when the HTL was thermally annealed by heating at $120{ }^{\circ} \mathrm{C}$ for 20 minutes, a significant improvement of the PCE up to 5.94\% was achieved with $V_{\mathrm{oc}}, J_{\mathrm{sc}}$ and FF being $0.76 \mathrm{~V}, 15.15 \mathrm{~mA} \mathrm{~cm}^{-2}$ and $51.52 \%$, respectively (Fig. 4 and Table 1, entry 2). This improvement of the PCE is due to the significant increase of FF with slightly improved $J_{\mathrm{sc}}$, while no noticeable change of $V_{\mathrm{oc}}$ has

Table 1 Solar cell parameters of the devices from the solutionprocessable HTL of CUSCN and donor materials with $\mathrm{PC}_{71} \mathrm{BM}$ of active area $6.0 \mathrm{~mm}^{2}$

\begin{tabular}{lllllll}
\hline \multicolumn{3}{c}{$\begin{array}{l}\text { Annealed condition Donor } \\
\text { Entry for the HTL }\end{array}$} & $\begin{array}{l}J_{\mathrm{sc}} \\
\text { materials }\end{array}\left(\mathrm{mA} \mathrm{cm}{ }^{-2}\right)$ & $\begin{array}{l}V_{\mathrm{oc}} \\
(\mathrm{V})\end{array}$ & $\begin{array}{l}\mathrm{FF} \\
(\%)\end{array}$ & $\mathrm{PCE}^{a}(\%)$ \\
\hline 1 & $90{ }^{\circ} \mathrm{C}$ for $20 \mathrm{~min}$ & PCDTBT & 14.89 & 0.76 & 37.39 & $4.22(4.07)$ \\
2 & $120{ }^{\circ} \mathrm{C}$ for $20 \mathrm{~min}$ & PCDTBT & 15.15 & 0.76 & 51.52 & $5.94(5.65)$ \\
3 & $90{ }^{\circ} \mathrm{C}$ for $20 \mathrm{~min}$ & PTB7 & 16.25 & 0.74 & 30.77 & $3.71(3.62)$ \\
4 & $120{ }^{\circ} \mathrm{C}$ for $20 \mathrm{~min}$ & PTB7 & 16.93 & 0.76 & 35.58 & $4.60(4.42)$
\end{tabular}

${ }^{a}$ In parentheses the average PCE of 4 devices is given. 


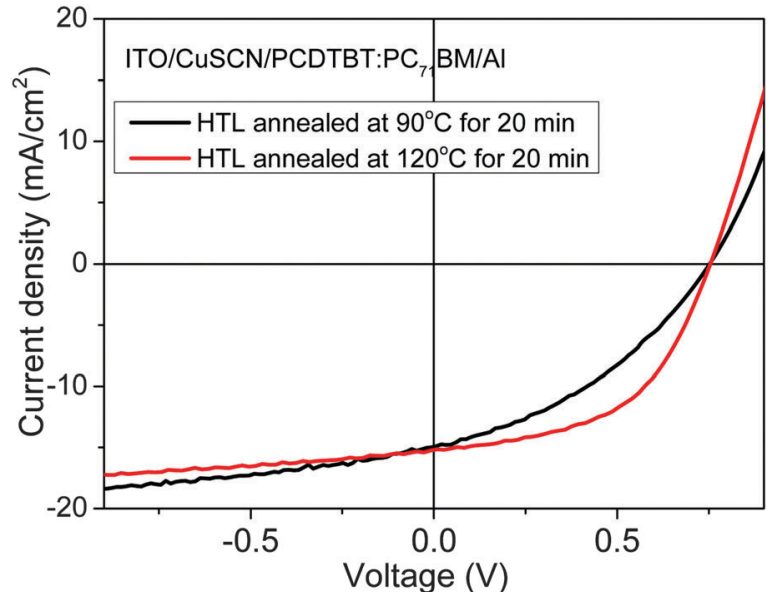

Fig. $4 \quad J-V$ curves for organic photovoltaic (OPV) device performance for ITO/CuSCN/PCDTBT:PC ${ }_{71}$ BM/Al geometry. (black line) HTL was annealed at $90{ }^{\circ} \mathrm{C}$ for 20 minutes; (red line) $\mathrm{HTL}$ was annealed at $120{ }^{\circ} \mathrm{C}$ for 20 minutes.

been observed. Thus the HTL annealed at $120{ }^{\circ} \mathrm{C}$ for 20 minutes may have improved the mobility, morphology and nanoscale phase separation for better contact which causes the enhancement of the PCE. ${ }^{34}$ Both the corresponding dark curves are shown in Fig. S1 (ESI $\dagger$ ).

For comparison purposes, photovoltaic devices have been fabricated using both $\mathrm{MoO}_{3}$ by thermal deposition ${ }^{35}$ and PEDOT:PSS by solution-processed ${ }^{36}$ methods as HTLs, respectively, for the device geometry of ITO/HTL/PCDTBT:PC ${ }_{71} \mathrm{BM} / \mathrm{Al}$ and under similar conditions. We have found that the device made from $\mathrm{MoO}_{3}$ as an HTL shows low performance compared to CuSCN as an HTL by the solution-processable method (Fig. S2, ESI $\dagger$ ). This is due to the lower values of $J_{\mathrm{sc}}$ and $V_{\mathrm{oc}}$, while no noticeable change of $\mathrm{FF}$ has been found. ${ }^{35}$ On the other hand solar cells fabricated from PEDOT:PSS as an HTL show significantly lower performance (Fig. S3, ESI $\dagger$ ) ${ }^{36}$ These results clearly demonstrated that solution-processable CuSCN is an even better HTL compared to both thermally deposited $\mathrm{MoO}_{3}$ and solution-processed PEDOT:PSS, respectively, for photovoltaic applications.

In order to further examine CuSCN as an efficient HTL for low band polymers, we have considered the most successfully used PTB7 as a donor material blended with $\mathrm{PC}_{71} \mathrm{BM}$ as an acceptor. CuSCN as an HTL was deposited from diisopropyl sulfide solution on ITO coated glass. The obtained HTL was annealed by heating at $90{ }^{\circ} \mathrm{C}$ for 20 minutes. Then the active layer and the metal cathode were deposited successively to complete the photovoltaic device with the structure of ITO/ CuSCN/PTB7:PC ${ }_{71} \mathrm{BM} / \mathrm{Al}$. The resulting device exhibits a PCE of $3.71 \%$ with $V_{\mathrm{oc}}, J_{\mathrm{sc}}$ and FF being $0.74 \mathrm{~V}, 16.25 \mathrm{~mA} \mathrm{~cm}{ }^{-2}$ and $30.77 \%$, respectively (Fig. 5 and Table 1, entry 3). When the HTL was annealed at $120{ }^{\circ} \mathrm{C}$ for 20 minutes a significant improvement of the PCE up to $4.60 \%$ has been achieved (Fig. 5 and Table 1, entry 4), as previously found for the PCDTBT:PC ${ }_{71} \mathrm{BM}$ active layer. However, the FF is lower due to the slight S-shape of the $J-V$ curve originating from surface recombination and blocking contacts caused by interfacial layers. The corresponding

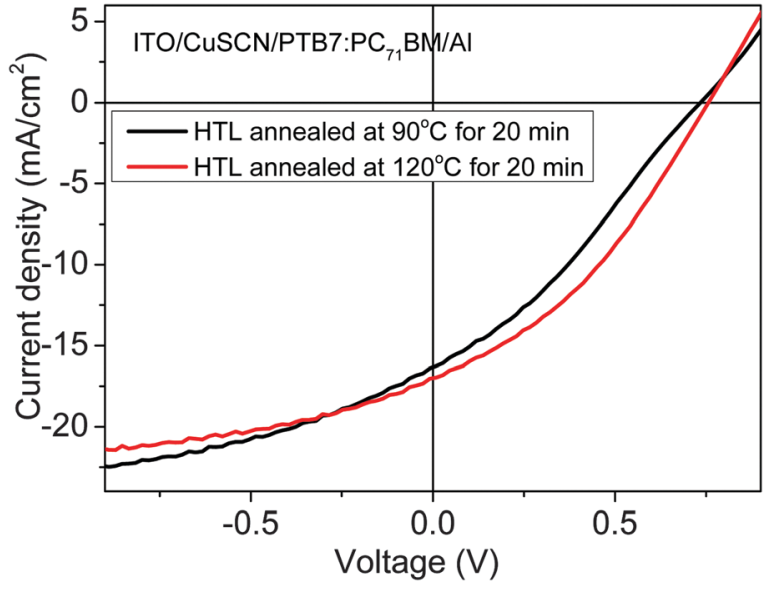

Fig. $5 \mathrm{~J}-\mathrm{V}$ curves for OPV device performance for ITO/CuSCN/ PTB7:PC ${ }_{71} \mathrm{BM} / \mathrm{Al}$ geometry. (black line) $\mathrm{HTL}$ was annealed at $90{ }^{\circ} \mathrm{C}$ for 20 minutes; (red line) $\mathrm{HTL}$ was annealed at $120^{\circ} \mathrm{C}$ for 20 minutes.

dark curves are presented in Fig. S4 (ESI $\dagger$ ). It may be mentioned here that in this study, PTB7 shows a poor PCE due to the lower FF compared to PCDTBT, although PTB7 is a more efficient donor material than PCDTBT. ${ }^{37}$

\subsection{Absorption and transmission of the HTL}

Optical absorption of CuSCN thin film on a quartz substrate was measured to investigate the absorption across the range of the solar spectrum (Fig. 6). The wide optical band gap ${ }^{23}$ of CuSCN film shows partially no absorption in the range of 500$1110 \mathrm{~nm}$, while it shows absorption in the UV region $(<500 \mathrm{~nm})$. It is noted that PEDOT:PSS films exhibit significant absorption in the vis-NIR region due to the presence of polarons and bipolarons, which are generated by oxidative doping. Thus it is clear that the CuSCN layer shows significantly lower parasitic absorption which makes it an efficient HTL in solar cells for further improvement of the PCE. The wired behavior at around $350 \mathrm{~nm}$ in absorption and transmission spectra

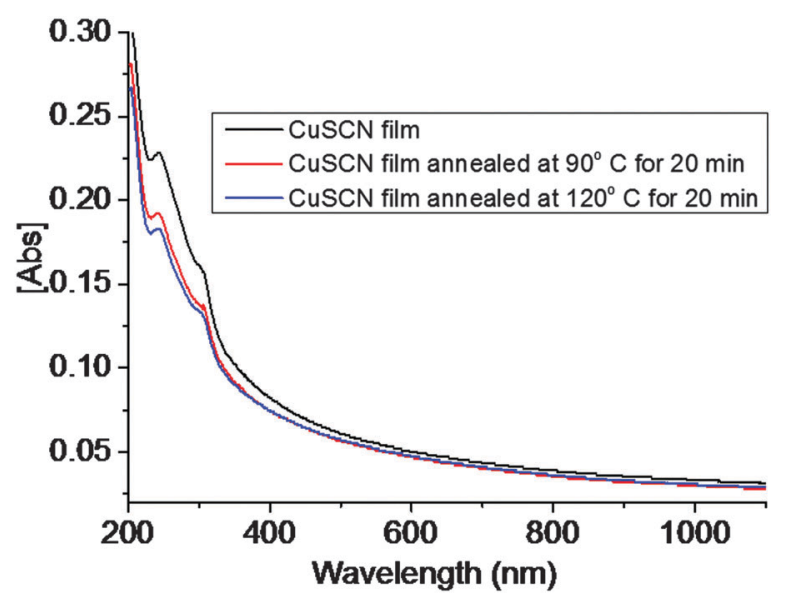

Fig. 6 UV-vis-NIR absorption spectra of CuSCN thin films on a quartz substrate. (black) as-prepared, (red) annealed at $90{ }^{\circ} \mathrm{C}$ for $20 \mathrm{~min}$ and (blue) annealed samples at $120{ }^{\circ} \mathrm{C}$ for $20 \mathrm{~min}$. 


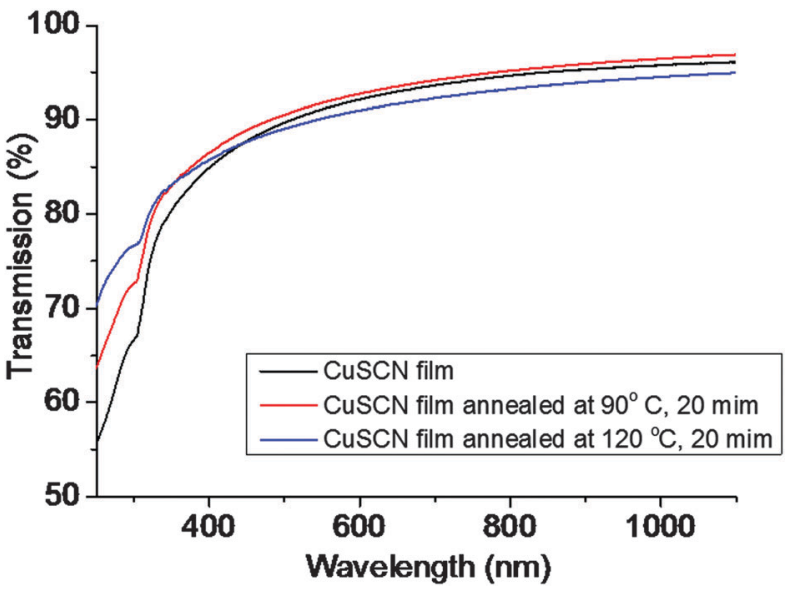

Fig. 7 Transmission spectra of CuSCN thin films on the quartz substrate. (black) as-prepared, (red) annealed at $90{ }^{\circ} \mathrm{C}$ for $20 \mathrm{~min}$ and (blue) annealed samples at $120^{\circ} \mathrm{C}$ for $20 \mathrm{~min}$.

(Fig. 6 and 7 respectively) are may be due to the excitation of electrons from sub-bands in the valence band to the conduction band. We note that earlier studies on the optical properties of CuSCN reported similar behavior.

In order to understand the improvement of PCE of the devices after the annealing of the HTL, experiments were undertaken to measure the effect of temperature on the optical properties of the HTL. Absorption and transmission measurements of the as-prepared CuSCN thin film and annealed CuSCN thin films (at $90{ }^{\circ} \mathrm{C}$ for 20 minutes and $120{ }^{\circ} \mathrm{C}$ for 20 minutes) are presented in Fig. 6 and 7, respectively. Remarkably, we did not observe any significant difference in the absorption and transmission spectra of the CuSCN film after annealing. This indicates that the enhancement may originate from the morphological improvement of the HTL due to annealing at higher temperature. ${ }^{38,39}$ This may originate from the higher boiling point of diisopropyl sulfide $\left(142{ }^{\circ} \mathrm{C}\right)$ used for the deposition of CuSCN as an HTL.

\subsection{Morphological studies}

In order to understand the better photovoltaic performance due to the annealing temperature, SEM images of CuSCN films are shown in Fig. 8. The films were prepared by spin coating on a glass substrate followed by annealing at $90{ }^{\circ} \mathrm{C}$ for 20 minutes and $120{ }^{\circ} \mathrm{C}$ for 20 minutes, respectively. We have found that both films have a smooth surface rather than a rough surface which might have facilitated good contact between the HTL and the active layer. SEM images of the HTL from the thermal deposition of $\mathrm{MoO}_{3}$ and solution processed PEDOT:PSS are also presented in the supporting information (Fig. S5, ESI $\dagger$ ). To understand the film morphology at an even better scale, AFM studies in air were performed on CuSCN film. The annealed CuSCN film was relatively smooth, with root mean square
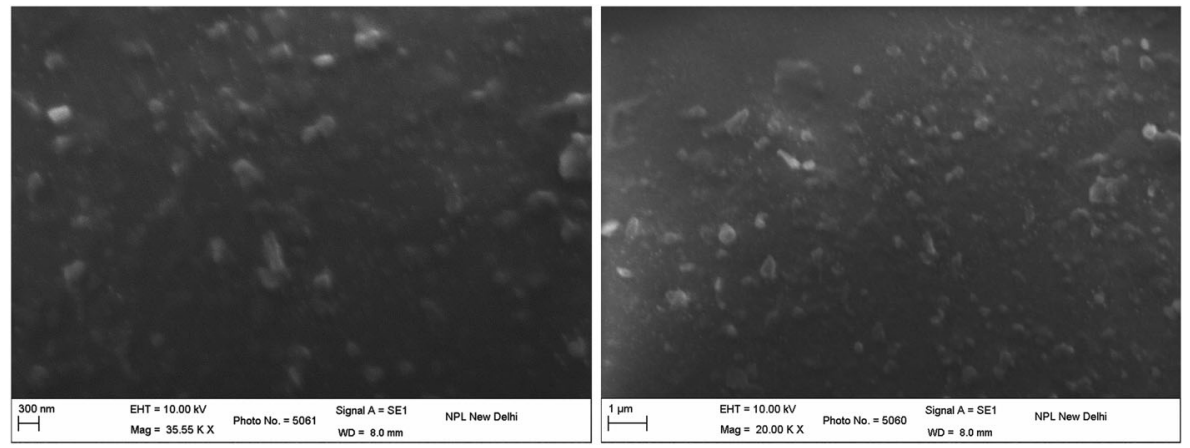

Fig. 8 SEM image of CuSCN film annealed at (left) $90{ }^{\circ} \mathrm{C}$ for 20 minutes and (right) $120{ }^{\circ} \mathrm{C}$ for 20 minutes on glass substrate.

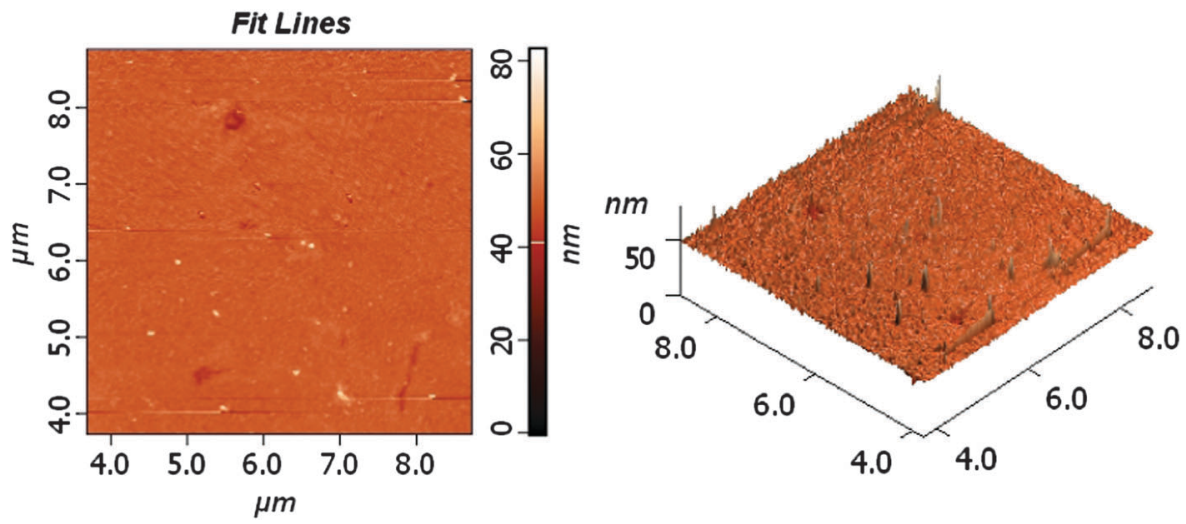

Fig. 9 AFM surface images of a spin coated CuSCN film on glass after annealing at $120^{\circ} \mathrm{C}$ for 20 minutes; (left) 2D image and (right) 3D image. 

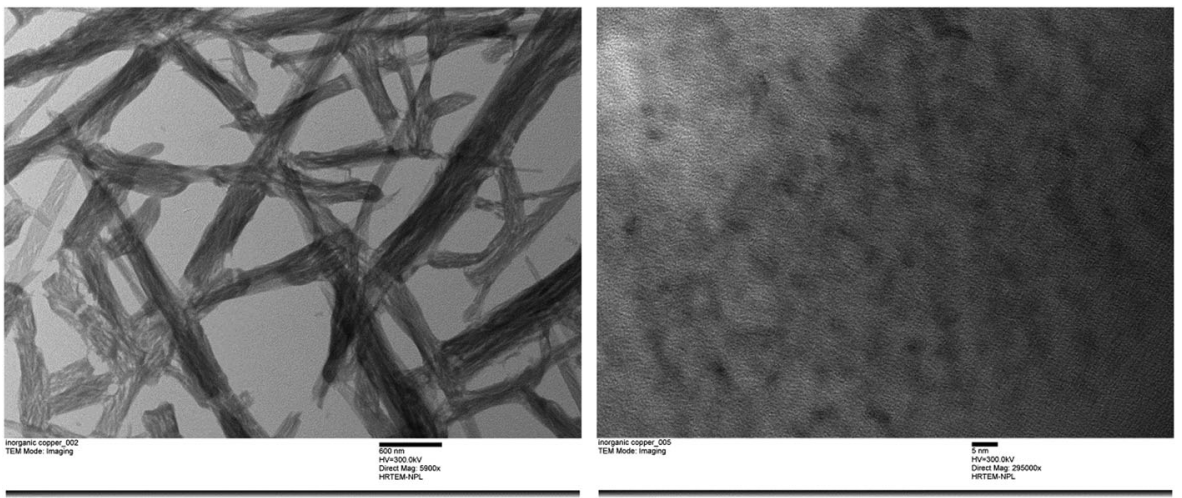

Fig. 10 TEM images of the CuSCN film (left: scale bar $600 \mathrm{~nm}$ and right: scale bar $5 \mathrm{~nm}$ )

(RMS) roughness and average roughness being $1.82 \mathrm{~nm}$ and $1.12 \mathrm{~nm}$, respectively (Fig. 9). It is also mentioned here that the PEDOT:PSS film shows a smoother morphology, while CuSCN films appear as a nanocrystalline surface. The drop-coated CUSCN film has been studied by TEM. The TEM image of the CuSCN film indicates the presence of a nanowire type structure revealing the mounds to be nanocrystalline as shown in Fig. 10.

\section{Conclusions}

In summary, conventional BHJ solar cells based on solutionprocessable CuSCN as an HTL has been fabricated using the simplest device geometry of ITO/CuSCN/active layer/Al. Three different combinations of the most studied and successfully used donor:acceptor materials (P3HT:PC ${ }_{61} \mathrm{BM}$, PCDTBT:PC ${ }_{71} \mathrm{BM}$ and PTB7:PC ${ }_{71} \mathrm{BM}$ ) were used and demonstrated that the solutionprocessable CuSCN as an HTL leads to efficient hole extraction. The use of CuSCN has improved light absorption within the active layer and thereby leads to up to $5.94 \%$ and $4.60 \%$ PCEs for active layers of PCDTBT: $\mathrm{PC}_{71} \mathrm{BM}$ and $\mathrm{PTB} 7: \mathrm{PC}_{71} \mathrm{BM}$, respectively. These results are slightly better when compared to the cells fabricated using thermal deposition of $\mathrm{MoO}_{3}$ and solution processed deposition of PEDOT:PSS as HTLs under similar conditions. The annealing temperature for the HTLs in organic solar cells has a significant effect on the PCE, specifically the FF and $J_{\mathrm{sc}}$. We have provided further examples of solution-processable CuSCN as an efficient HTL in organic solar cells, in general. This study clearly demonstrates that there is a further opportunity to optimize the solution-processable CUSCN as an HTL to improve the PCE and lifetime of the device with a wide range of materials being under process in our laboratory.

\section{Acknowledgements}

This work is financially support by the CSIR-TAPSUN (NWP-54) program.

\section{References}

1 Z. B. Henson, K. Müllen and G. C. Bazan, Nat. Chem., 2012, 4, 699-704.
2 Y.-J. Cheng, S.-H. Yang and C.-S. Hsu, Chem. Rev., 2009, 109, 5868-5923.

3 P. M. Beaujuge and J. M. J. Fréchet, J. Am. Chem. Soc., 2011, 133, 20009-20029.

4 H. Dong, H. Zhu, Q. Meng, X. Gong and W. Hu, Chem. Soc. Rev., 2012, 41, 1754-1808.

5 L. Ye, S. Zhang, L. Huo, M. Zhang and J. Hou, Acc. Chem. Res., 2014, 47, 1595-1603.

6 Z. E. Jouad, M. Morsli, G. Louarn, L. Cattin, M. Addou and J. C. Bernède, Sol. Energy Mater. Sol. Cells, 2015, 141, 429-435.

7 B. Roth, G. A. dos Reis Benatto, M. Corazza, R. R. Søndergaard, S. A. Gevorgyan, M. Jørgensen and F. C. Krebs, Adv. Energy Mater., 2015, 4, 1401912.

8 M. Jorgensen, K. Norrman and F. C. Krebs, Sol. Energy Mater. Sol. Cells, 2008, 92, 686-714.

9 B. Ecker, J. Posdorfer and E. von Hauff, Sol. Energy Mater. Sol. Cells, 2013, 116, 176-181.

10 M. Jørgensen, K. Norrman, S. A. Gevorgyan, T. Tromholt, B. Andreasen and F. C. Krebs, Adv. Mater., 2012, 24, 580-612.

11 A. W. Hains, C. Ramanan, M. D. Irwin, J. Liu, M. R. Wasielewski and T. J. Marks, ACS Appl. Mater. Interfaces, 2010, 2, 175-185.

12 S. S. Li, K. H. Tu, C. C. Lin, C. W. Chen and M. Chhowalla, ACS Nano, 2010, 4, 3169-3174.

13 J. Liu, Y. Xue, Y. Gao, D. Yu, M. Durstock and L. Dai, Adv. Mater., 2012, 24, 2228-2233.

14 S. Shao, J. Liu, J. Bergqvist, S. Shi, C. Veit, U. Würfel, Z. Xie and F. Zhang, Adv. Energy Mater., 2013, 3, 349-355.

15 E. L. Ratcliff, J. Meyer, K. X. Steirer, N. R. Armstrong, D. Olson and A. Kahn, Org. Electron., 2012, 13, 744-749.

16 Y. Sun, C. J. Takacs, S. R. Cowan, J. H. Seo, X. Gong, A. Roy and A. J. Heeger, Adv. Mater., 2011, 23, 2226-2230.

17 P. Qin, G. Fang, F. Cheng, W. Ke, H. Lei, H. Wang and X. Zhao, ACS Appl. Mater. Interfaces, 2014, 6, 2963-2973.

18 (a) Z. Tan, L. Li, F. Wang, Q. Xu, S. Li, G. Sun, X. Tu, X. Hou, J. Hou and Y. Li, Adv. Energy Mater., 2014, 4, 1300884; (b) V. Shrotriya, G. Li, Y. Yao, C. Chu and Y. Yang, Appl. Phys. Lett., 2006, 88, 073508.

19 H. Pan, L. Zuo, W. Fu, C. Fan, B. Andreasen, X. Jiang, K. Norrman, F. C. Krebs and H. Chen, Org. Electron., 2013, 14, 797-803. 
20 (a) K. Tennakone and W. M. Ariyasingha, Electrochim. Acta, 1980, 25, 731; (b) B. O'Regan and D. T. Schwartz, Chem. Mater., 1995, 7, 1349-1354; (c) B. O’Regan, D. T. Schwartz, S. M. Zakeeruddin and M. Grätzel, Adv. Mater., 2000, 12, 1263-1267.

21 A. Perumal, H. Faber, N. Yaacobi-Gross, P. Pattanasattayavong, C. Burgess, S. Jha, M. A. McLachlan, P. N. Stavrinou, T. D. Anthopoulos and D. D. C. Bradley, Adv. Mater., 2015, 27, 93-100.

22 P. Pattanasattayavong, G. O. N. Ndjawa, K. Zhao, K. W. Chou, N. Yaacobi-Gross, B. C. O'Regan, A. Amassian and T. D. Anthopoulos, Chem. Commun., 2013, 49, 4154-4156.

23 P. Pattanasattayavong, N. Yaacobi-Gross, K. Zhao, G. O. N. Ndjawa, J. Li, F. Yan, B. C. O’Regan, A. Amassian and T. D. Anthopoulos, Adv. Mater., 2013, 25, 1504-1509.

24 G. Kumara, A. Konno, G. K. R. Senadeera, P. V. V. Jayaweera, D. D. Silva and K. Tennakone, Sol. Energy Mater. Sol. Cells, 2001, 69, 195-199.

25 P. Qin, S. Tanaka, S. Ito, N. Tetreault, K. Manabe, H. Nishino, M. K. Nazeeruddin and M. Gratzel, Nat. Commun., 2014, 5, 3834.

26 C. Chappaz-Gillot, S. Berson R. Salazar, B. Lechêne, D. Aldakov, V. Delaye, S. Guillerez and V. Ivanova, Sol. Energy Mater. Sol. Cells, 2014, 120, 163-167.

27 S. Ye, W. Sun, Y. Li, W. Yan, H. Peng, Z. Bian, Z. Liu and C. Huang, Nano Lett., 2015, 15, 3723-3728.

28 N. Yaacobi-Gross, N. D. Treat, P. Pattanasattayavong, H. Faber, A. K. Perumal, N. Stingelin, D. D. C. Bradley, P. N. Stavrinou, M. Heeney and T. D. Anthopoulos, Adv. Energy Mater., 2014, 5, 1401529.

29 N. D. Treat, N. Yaacobi-Gross, H. Faber, A. K. Perumal, D. D. C. Bradley, N. Stingelin and T. D. Anthopoulos, Appl. Phys. Lett., 2015, 107, 013301.

30 M. T. Dang, L. Hirsch and G. Wantz, Adv. Mater., 2011, 23, 3597-3602.

31 S. Beaupré and M. Leclerc, J. Mater. Chem. A, 2013, 1, 11097-11105.

32 (a) F. He and L. Yu, J. Phys. Chem. Lett., 2011, 2, 3102-3113; (b) L. Ye, S. Zhang, W. Zhao, H. Yao and J. Hou, Chem. Mater., 2014, 26, 3603-3605.
33 We have examined CuSCN as an HTL for the fabrication of OPV devices with the geometry of ITO/CuSCN/P3HT:PC ${ }_{61} \mathrm{BM} /$ $\mathrm{Al}$ and the resulting devices exhibit poor efficiency. We also used different thicknesses of the HTL by using different concentrations of the CuSCN solution and no significant improvement of the efficiency has been found.

34 E. Verploegen, R. Mondal, C. J. Bettinger, S. Sok, M. F. Toney and Z. Bao, Adv. Funct. Mater., 2010, 20, 3519.

35 OPV devices were fabricated using the thermal deposition of $\mathrm{MoO}_{3}$ as a HTL with the geometry of ITO/ $\mathrm{MoO}_{3}(10 \mathrm{~nm}) /$ PCDTBT:PC ${ }_{71} \mathrm{BM} / \mathrm{Al}$ and PCE $5.25 \%$ with $J_{\mathrm{sc}}, V_{\mathrm{oc}}$ and $\mathrm{FF}$ being $10.8 \mathrm{~mA} \mathrm{~cm}{ }^{-2}, 0.89 \mathrm{~V}$ and $54.9 \%$, respectively, under similar conditions as described. See details in the ESI $\dagger$.

36 For comparison purposes we also fabricated the OPV devices using solution-processable PEDOT:PSS as an HTL under similar conditions and found a PCE of $3.22 \%$ with $J_{\mathrm{sc}}$,

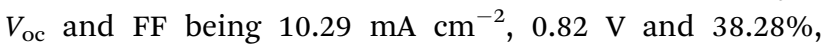
respectively. The poor performance is mainly due to the significantly lower FF and $J_{\text {sc. }}$.

37 As described previously in the literature, PTB7 is a lower band gap polymer compared to PCDTBT and earlier studies demonstrated that devices made with the PCDTBT polymer are more stable than PTB7. Indeed under ambient condition, PTB7 is slightly oxide. As a result the device made with PTB7 shows lower PCE. Moreover, the poor performance may originate from the interfacial energy alignment because of the HOMO level of PTB7 $(-5.15 \mathrm{eV})$ is $0.2 \mathrm{eV}$ higher compared to the energy level of CuSCN (work function $\sim-5.35 \mathrm{eV}$ ), whereas the HOMO level of PCDTBT is $0.15 \mathrm{eV}$ lower lying $(-5.5 \mathrm{eV})$.

38 N. Zhou, H. Lin, S. J. Lou, X. Yu, P. Guo, E. F. Manley, S. Loser, P. Hartnett, H. Huang, M. R. Wasielewski, L. X. Chen, R. P. H. Chang, A. Facchetti and T. J. Marks, Adv. Energy Mater., 2014, 4, 1300785.

39 C. D. Wessendorf, G. L. Schulz, A. Mishra, P. Kar, I. Ata, M. Weidelener, M. Urdanpilleta, J. Hanisch, E. Mena-Osteritz, M. Lindén, E. Ahlswede and P. Bäuerle, Adv. Energy Mater., 2014, 4, 1400266. 